\title{
LONG-TIME INVESTIGATION OF CEMENT PASTES WITH MICRONIZED OLD CONCRETE, INFLUENCE OF DIFFERENT TYPE OF MIXING APPROACH ON MECHANICAL PROPERTIES
}

\author{
ZdenĚK PRošEK ${ }^{a, b, *}$, PAVEl TesÁReK $^{a}$ \\ ${ }^{a}$ Czech Technical University in Prague, Faculty of Civil Engineering, Department of Mechanics, Thákurova 7 , \\ 16629 Prague 6, Czech Republic \\ ${ }^{b}$ Czech Technical University in Prague, UCEEB, Třinecká 1024, 27343 Buštěhrad, Czech Republic \\ * corresponding author: zdenek.prosek@fsv.cvut.cz
}

\begin{abstract}
The article focuses on the impact of different type of mixing approach on resulting mechanical properties of cement composites. The monitored parameters of the mixing approach were the speed of mixing and the method of mixing the individual components of the fresh mixture. The mechanical properties of the resulting composites were the main comparative parameter. The determined mechanical properties were dynamic modulus of elasticity, dynamic shear modulus, flexural strength and compressive strength. Dynamics moduli were detected using non-destructive resonance method during the whole experiment and compressive and flexural strength were determined by destructive method for 28 and 129 days old samples. Testing samples had dimensions equal to $40 \times 40 \times 160 \mathrm{~mm}$.
\end{abstract}

KEYWORDs: Cement composites, recycled old concrete, mixing approach, mechanical properties, long-time development.

\section{INTRODUCTION}

At present, the cement based composite materials (in the form of monolithic reinforced concrete, prefabricated elements, fittings etc.) present the most widespread and widely used building material. However, from the perspective of sustainable development, three basic components are needed for production cement, sand and water. Their extraction, treatment and processing represent a burden on nature and the environment [1] 3]. In particular, cement production represents $7 \%$ of global $\mathrm{CO}_{2}$ production and large amount of $\mathrm{NO}_{x}$. Water consumption is also not desirable, it would be appropriate to reduce it. In many locations (e. g. the Middle East), there is lack of construction sand or cement, the problem is solved by transporting it from distant locations, for example, Saudi Arabia imports suitable sand from Australia and Israel imports cement from Turkey [4 6].

On the other hand, there are alternative options in the form of green composite or green concrete using alternative sources of raw materials, even secondary ones, eg. old waste concrete. The amount of waste old concrete is growing year after year and the need for its efficient use with it 7, , 8. Nowadays it is relatively common to use recycled aggregate from concrete into new concrete, mostly fraction 1/16 mm [9, 10. There are several types of treatments to suitably adjust the surface of recycled aggregate to function properly in new concrete, but even these solutions have some limitations. On the other hand, fraction $0 / 1 \mathrm{~mm}$ of recycled concrete remains out of focus whether the professional or corporate (construction industry) and this fraction is estimated to be up to $20 \mathrm{wt}$. \% of recy- cled concrete. After suitable treatment, this material can be advantageously used in cementitious composite materials, for example by mechanical-chemical activation 11, 12.

The properties of the resulting composite are not only directly dependent on the grain shape which is not suitable in the case of recycled concrete but also on the size of the interfacial transition zone (ITZ). These effects have a negative influence on the resulting properties [13]. Recently, there have been studies in which the ITZ can be partially eliminated using the correct mixing approach, i.e., the correct procedure of mixing of the components of the cement composite and the mixing speed [14, 15].

Unlike mentioned researches which they focus on recycled coarse aggregate, we focused on mechanical activated old concrete. This is fine aggregate with modified grain shape by using high-speed milling process [16]. The micronizing of the old cement paste into fine particle results in uncovered unhydrated clinker minerals, which can further hydrate upon contact with water [17.

\section{MATERIALS AND SAMPLES}

Cement pastes samples were created to tests the mechanical properties. Cement pastes composed of 50 wt. \% Portland cement CEM I 42.5R from Radotin and 50 wt. \% fine recycled old concrete (ROC) has been prepared for investigating the impact of different mixing approach. The CEM I 42.5R is ordinary Portland cement with high content of $\mathrm{C}_{3} \mathrm{~S}$ (approximately $75 \%$ ) and low content of $\mathrm{C}_{2} \mathrm{~S}$ and $\mathrm{C}_{3} \mathrm{~A}(<8 \%)$. ROC was obtained from an old construction concrete (sleep- 


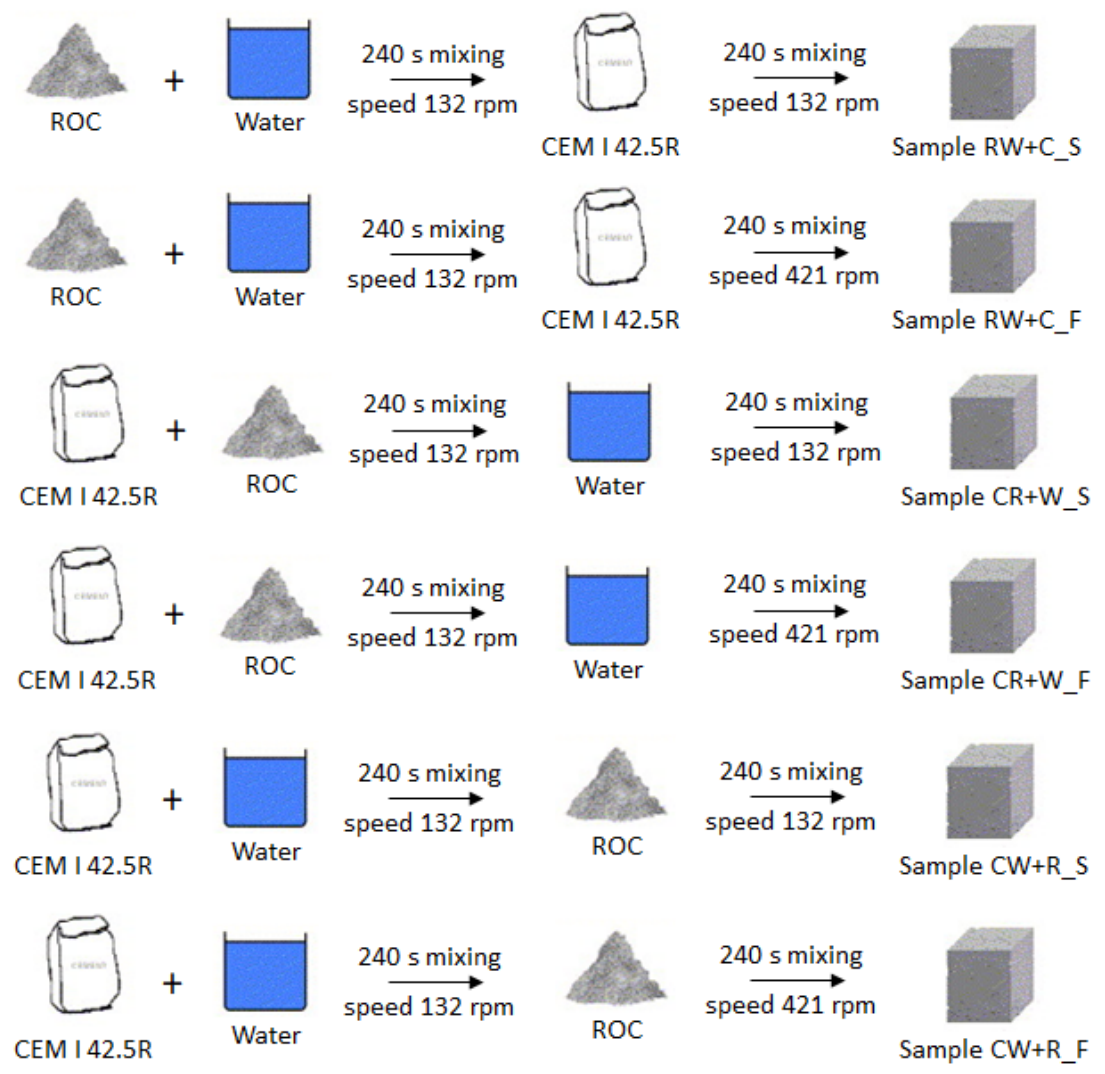

Figure 1. Approach of mixing fresh mixtures.

ers and columns with fraction $0 / 1 \mathrm{~mm}$ ), which was micronized using a high-speed mill from Lavaris Ltd. (Libčice, Czech Republic). The micronized ROC with fraction $0-0.5 \mathrm{~mm}$ had mean grain size of $61.8 \mathrm{mi}$ crons and more than $90 \%$ of all grains were less than 281 microns Water ratio was equal to 0.35 . The difference between individual samples was in the approach of mixing fresh mixtures. Two different components were mixed at $132 \mathrm{rpm}$ for 240 seconds in the first step of the mixture preparation. In the second step, the remaining third component was added and the mixtures were mixed for 240 seconds at two different speeds, namely $132 \mathrm{rpm}$ and $421 \mathrm{rpm}$. The mixing approaches are shown in Figure 1 .

Mixtures made according to Figure 1 were cast to the rectangular molds with dimensions $40 \times 40 \times 160 \mathrm{~mm}$. After casting, these samples were kept in the molds for $24 \mathrm{~h}$ at the laboratory with the temperature $22{ }^{\circ} \mathrm{C}$. Each set consisted of 6 samples. After demolding, these samples were deposited in in a water bath at $22 \pm 1{ }^{\circ} \mathrm{C}$.

\section{EXPERIMENTAL METHODS}

Investigated mechanical parameters were developments of dynamic modulus of elasticity and dynamic shear modulus and values of flexural strength and compressive strength. The development of the dynamic modulus of elasticity and dynamic shear modulus was measured non-destructively in the first 129 days after the start of cement hydration, namely at $10^{t h}, 14^{t h}$, $28^{t h}, 48^{t h}, 69^{t h}, 129^{t h}$ day. The flexural and compressive strength values were measured destructively on 28 and 129 day old samples.

Measurement of the dynamic modulus of elasticity was carried out by using resonance method, namely by the measurement apparatus from Brüel \& Kjær. The measurement line consisted of a measuring unit type 3560-B-X12, impact hammer type 8206, an acceleration transducer type 4519-00353422 and software PULSE LabShop. The dynamic modulus of elasticity calculated based on the measured basic longitudinal natural frequency and basic flexural natural frequency of the samples. The dynamic shear modulus calculated based on the measured basic torsional natural frequency of the samples.

The flexural and compressive strength were determined by using destructive methods on the device FHF Strassentest. The flexural strength was determined by a three-point bending test. The testing of flexural strength was displacement controlled at a constant rate of $1 \mathrm{~mm} / \mathrm{min}$. The distance between supports for three-point bending test was equal to $100 \mathrm{~mm}$. The compressive strength was determined by using uniaxial compressive test. The uniaxial compressive test was performed on the broken halves of the samples after bending test with effective dimensions of $40 \times 40 \times 40 \mathrm{~mm}$. The testing of compressive strength was displacement controlled at a constant rate of $5 \mathrm{~mm} / \mathrm{min}$. 


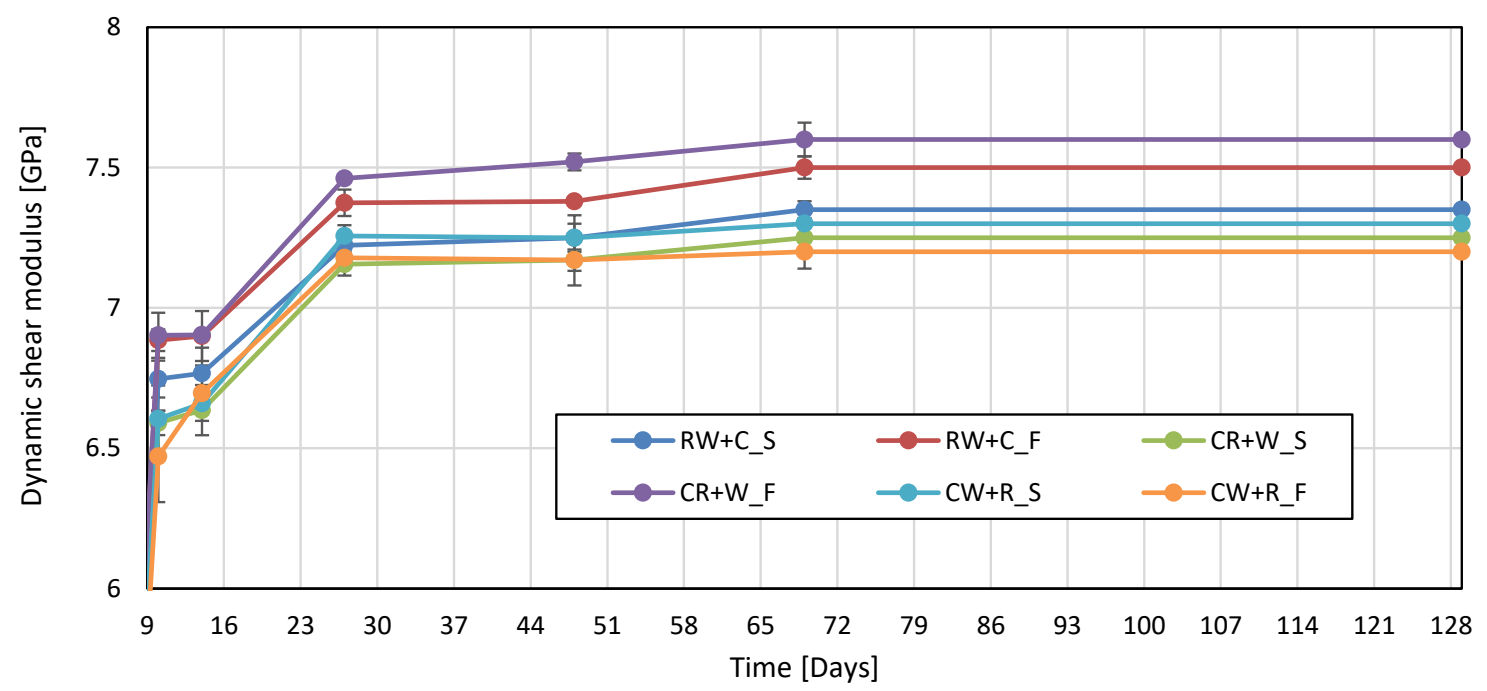

Figure 2. Time dependence of dynamic shear modulus (with standard deviation).

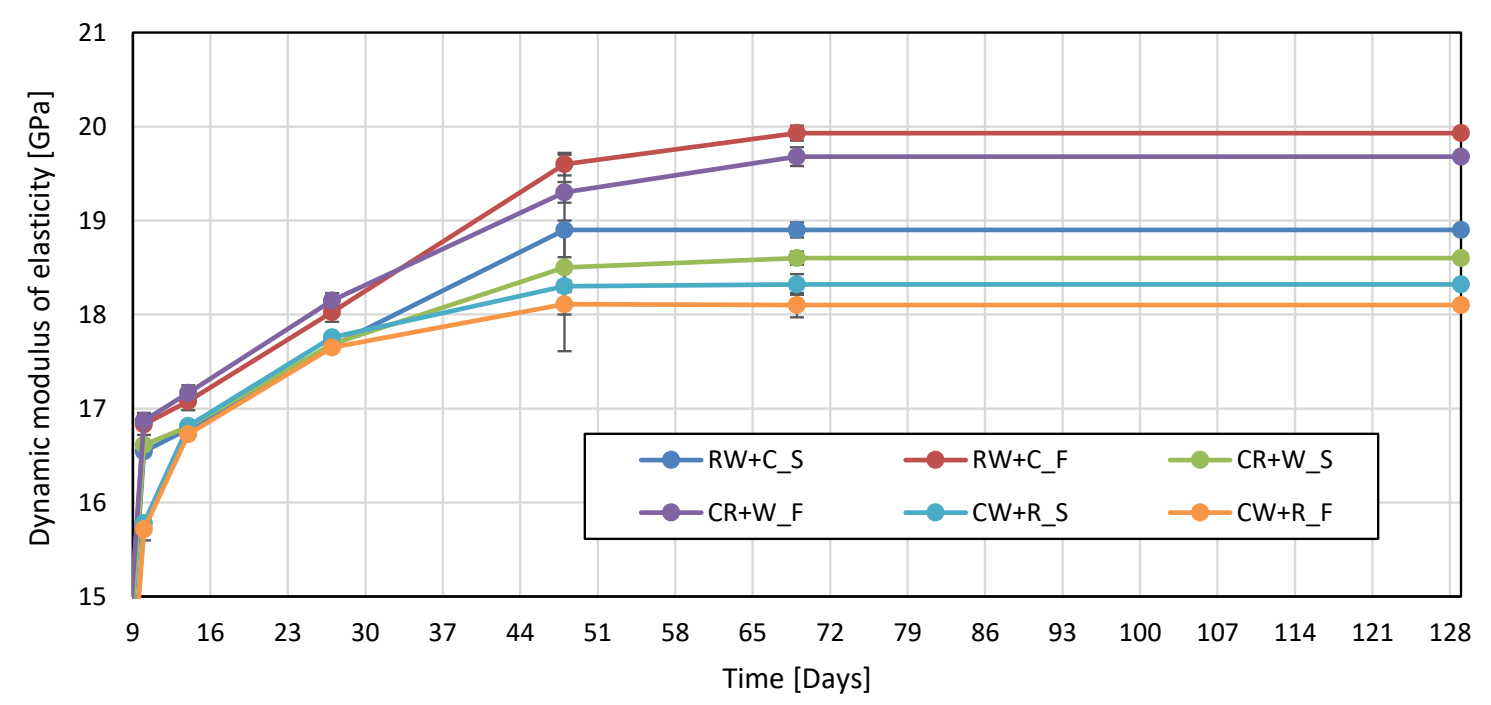

FiguRE 3. Time dependence of dynamic modulus of elasticity (with standard deviation).

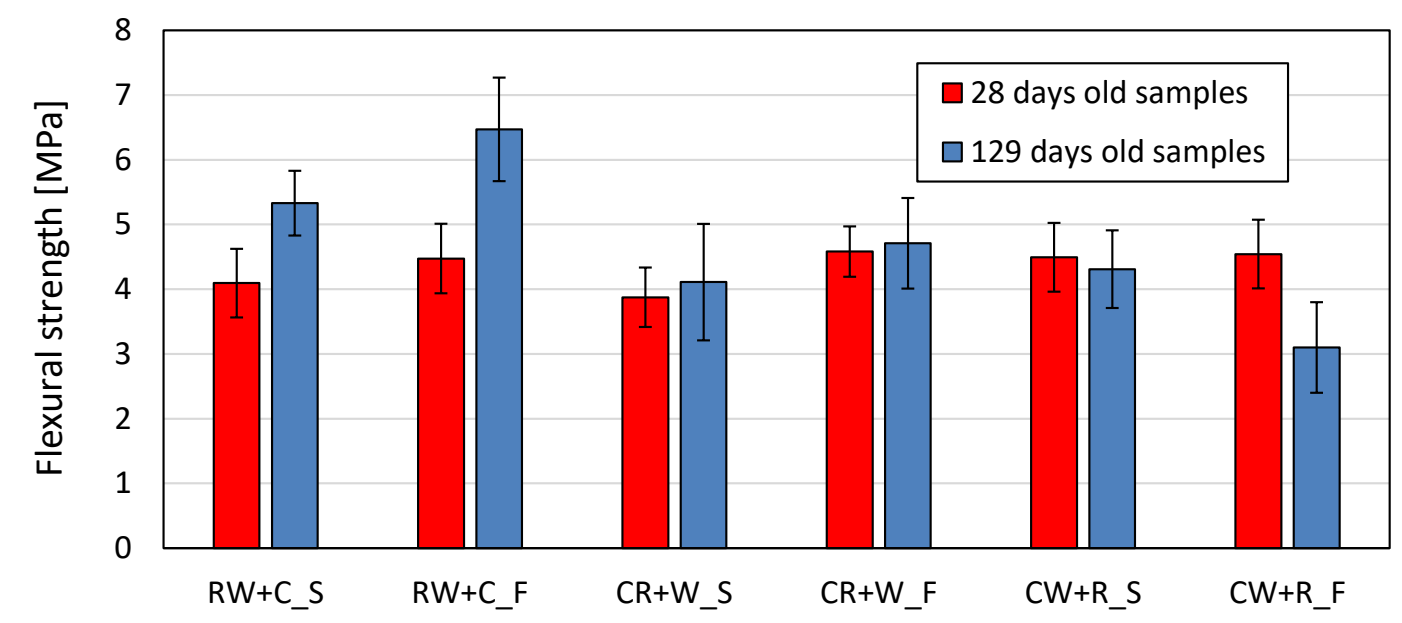

FIGURE 4. Flexural strength of the samples (with standard deviation). 


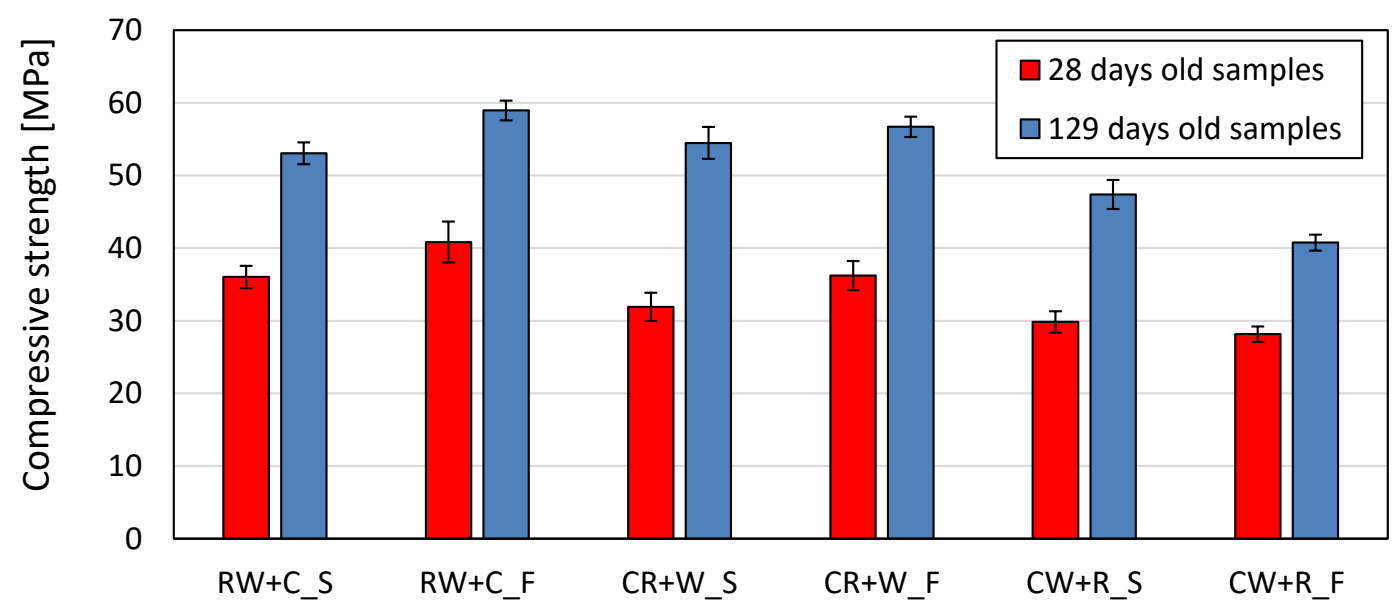

FiguRE 5. Compressive strength of the samples (with standard deviation).

\section{Results AND Discussion}

Results of non-destructive testing are shown in Figure2 and Figure 3 All samples must be measured and weighed before evaluating dynamic moduli. From the measured values it was possible to determine the bulk density. All tested mixtures had approximately the same bulk density, namely $1926 \pm 24 \mathrm{~kg} / \mathrm{m}^{3}$. The results of dynamic moduli show the positive effect of the mixing speed of the fresh mixture on the dynamic modulus of elasticity and the dynamic shear modulus. Differences between the highest and lowest values of moduli for 28 days old samples were between samples $\mathrm{CR}+\mathrm{W} \_\mathrm{S}$ and samples $\mathrm{CR}+\mathrm{W} \_\mathrm{F}$, namely $0.5 \mathrm{GPa}$ for dynamic modulus of elasticity and $0.3 \mathrm{GPa}$ for dynamic shear modulus. These differences are within the accuracy of the method. The highest increase of dynamic modulus of elasticity and dynamic shear modulus is in the first 14 days of the sample age. Furthermore, the increase in values is gradual in the next 34 days. After 48 days, there are minimal changes of dynamic moduli.

The flexural strength of 28 days old samples was approximately same value on all testing samples (Figure 4. Differences were up to the size of the value standard deviation. Value of flexural strength was 4.5 MPa for 28 days old samples. For the 129 day flexural strengths, there are greater differences between the individual mixtures than for the 28 day flexural strengths. Highest value of flexural strength had sample RW+C_F, namely $6.5 \pm 0.8 \mathrm{MPa}$. Lowest value of flexural strength had sample $\mathrm{CW}+\mathrm{R} \_\mathrm{F}$, namely $3.1 \pm 0.7 \mathrm{MPa}$, ie more than double the difference. In contrast of it, the compressive strength values (Figure 5 were different and they have the same trend as the values of dynamic modulus of elasticity. The greatest value of compressive strength for 28 days old samples had RW + C_F, namely $40.8 \pm 2.8 \mathrm{MPa}$ and lowest value of compressive strength had $\mathrm{CW}+\mathrm{R} \_\mathrm{F}$, namely $28.1 \pm 1.1 \mathrm{MPa}$. The difference between the compressive strength of 28 days old samples and 129 days old samples was approximately the same for all mixtures, namely $18 \mathrm{MPa}$. The increase in compressive strength between 28 and 192 days is due to a combination of two effects. The first effect is the hydration of $\mathrm{C}_{2} \mathrm{~S}$, which is contained in CEM I 42.5R (content approximately $8 \%$ ) and the second effect is the content of unhydrated clinkers in the ROC, where this content can be up to $10 \%$ [16. Value of standard deviation was approximately $5 \%$ of compressive strength value in all tested cases.

The results show that the mixing speed has a positive effect on the resulting compressive strength, with a difference of approximately $5 \mathrm{MPa}$ for slow and fast mixing of $\mathrm{RW}+\mathrm{C}$ and $4 \mathrm{MPa}$ for slow and fast mixing of $\mathrm{CR}+\mathrm{W}$. This is the effect of better homogenization of the fresh mixture by fast mixing. The mixture $\mathrm{RW}+\mathrm{C}$ (the old concrete was first mixed with water and then with the cement) had the highest compressive strength values, namely $5 \mathrm{MPa}$ higher than the mix where the old concrete was mixed with the cement at first. The mixture where the cement was mixed with water at first had the lowest compressive strength by about $5 \mathrm{MPa}$ lower than in the case of cement mixing with the old concrete at first and $10 \mathrm{MPa}$ lower than the mixture where the recycle was mixed with water at first. It is generally agreed that as the pasteaggregate bond strength increases (reducing of ITZ), the strength of cement composites also increases [18]. So the process of mixing the individual components of the cement composite affects the ITZ zone between the cement matrix and the recycle grains. Results of the work are in agreement with the statement of several authors, because the size of ITZ zone depends on the approach of mixing not only in recycled coarse aggregate but also in micronized recycled old concrete. This effect can be attributed to the porous nature of the recycled aggregate, and therefore the premix process may fill some pores and cracks, resulting in an improved inter transition zone around the recycled aggregate and hence higher strength compared to the traditional mixing approach [14. 


\section{Conclusion}

This work was focused on the influence of different type of mixing approach on mechanical properties of cement composites. The researched samples were composed of Portland cement (50 wt. \%) and micronized recycled old concrete $(50$ wt. \%). The difference between individual samples was in the approach of mixing fresh mixtures. Based on the results, it can be concluded that:

- approach of mixing fresh mixtures had influence on mechanical properties of resulting cement composites by reducing of ITZ,

- the greatest effect of type of mixing approach can be seen in the sample where water and micronized old recycled concrete were mixed in the first step and in the second step, the cement was added,

- the mixing speed has a positive effect on the resulting compressive strength, the change of mixing speed from $132 \mathrm{rpm}$ to $421 \mathrm{rpm}$ resulted in an increase of compressive strength of $5 \mathrm{MPa}$,

- there is an increase of compressive strength due to hydration of $\mathrm{C}_{2} \mathrm{~S}$ contained in Portland clinker of reference cement and in non-hydrated clinker of micronized recycled old concrete.

In the future, the research will focus on confirming influence on approach of mixing on ITZ by using scanning electron microscope with X-ray microanalysis, namely an Energy Spectrometer.

\section{ACKNOWLEDGEMENTS}

This paper was financially supported by the GA CR research a project under the number 17-06771S and by Czech Technical University in Prague under No. SGS project SGS19/148/OHK1/3T/11. The authors also thank the company LAVARIS Ltd, where a high-speed mill was used for micronizing of the recycled old concrete.

\section{REFERENCES}

[1] J. Schoon, K. De Buysser, I. Van Driessche, N. De Belie. Fines extracted from recycled concrete as alternative raw material for portland cement clinker production. Cement and Concrete Composites 58:70-80, 2015. DOI:10.1016/j.cemconcomp.2015.01.003

[2] R. V. Silva, J. De Brito, R. Dhir. Properties and composition of recycled aggregates from construction and demolition waste suitable for concrete production. Construction and Building Materials 65:201-217, 2014.

[3] A. Rana, P. Kalla, H. Verma, J. Mohnot. Recycling of dimensional stone waste in concrete: A review. Journal of cleaner production 135:312-331, 2016. DOI:10.1016/j.conbuildmat.2014.04.117.

[4] F. Pacheco-Torgal, Y. Ding. Handbook of recycled concrete and demolition waste. Elsevier, 2013.

[5] A. Yazdanbakhsh. A bi-level environmental impact assessment framework for comparing construction and demolition waste management strategies. Waste management 77:401-412, 2018. DOI:10.1016/j.wasman.2018.04.024
[6] B. Demirel. The effect of the using waste marble dust as fine sand on the mechanical properties of the concrete. International journal of physical sciences 5(9):1372-1380, 2010.

[7] C.-L. Peng, D. E. Scorpio, C. J. Kibert. Strategies for successful construction and demolition waste recycling operations. Construction Management \& Economics 15(1):49-58, 1997. DOI:10.1080/014461997373105.

[8] V. Corinaldesi, G. Moriconi. Behaviour of cementitious mortars containing different kinds of recycled aggregate. Construction and building materials 23(1):289-294, 2009. DOI:10.1016/j.conbuildmat.2007.12.006

[9] J. Xiao, W. Li, Y. Fan, X. Huang. An overview of study on recycled aggregate concrete in china (19962011). Construction and Building materials 31:364-383, 2012. DOI:10.1016/j.conbuildmat.2011.12.074

[10] K. Šeps, J. Vodička. Fibre reinforced concrete with recycled concrete and insulation material stered. In Advanced Materials Research, vol. 1054, pp. 262-266. Trans Tech Publ, 2014. DOI:10.4028/www.scientific.net/AMR.1054.262

[11] Z. Prošek, V. Nežerka, R. Hlǔžek, et al. Role of lime, fly ash, and slag in cement pastes containing recycled concrete fines. Construction and Building Materials 201:702-714, 2019. DOI:10.1016/j.conbuildmat.2018.12.227

[12] D. Pedro, J. De Brito, L. Evangelista. Influence of the use of recycled concrete aggregates from different sources on structural concrete. Construction and Building Materials 71:141-151, 2014. DOI:10.1016/j.conbuildmat.2014.08.030.

[13] A. K. Kwan, C. Mora, H. Chan. Particle shape analysis of coarse aggregate using digital image processing. Cement and Concrete Research 29(9):14031410, 1999. DOI:10.1016/S0008-8846(99)00105-2

[14] V. W. Tam, X. Gao, C. M. Tam. Microstructural analysis of recycled aggregate concrete produced from two-stage mixing approach. Cement and concrete research 35(6):1195-1203, 2005. DOI:10.1016/j.cemconres.2004.10.025.

[15] Z. Prošek, P. Tesárek, J. Trejbal, T. Plachý. Mechanical properties of cement pastes with fine old concrete, influence of different type of approach mixing. in print: EAN 2019 - 57TH CONFERENCE ON EXPERIMENTAL STRESS ANALYSIS 2019.

[16] Z. Prošek, P. Tesárek, V. Hrbek. Characterization of old concrete for new use: Grid nanoindentation and scanning electron microscopy. NANOCON 2018 Conference Proceedings, 10th Anniversary International Conference on Nanomaterials - Research and Application pp. 736-741, 2019.

[17] J. Hruza, J. Topič, Z. Prošek. Mechanical properties of the cement paste with fine ground recycled concrete depending on the microstructure. In Advanced Materials Research, vol. 1144, pp. 22-27. Trans Tech Publ, 2017. DOI:10.4028/www.scientific.net/AMR.1144.22,

[18] S. Mindess, J. Young, D. Darwin. Concrete. Prentice Hall, 2003. 